\title{
Knowledge, attitudes, beliefs, and practices of Chinese migrants in Nairobi, Kenya and Dar es Salaam, Tanzania toward HIV/AIDS
}

\author{
Guoxi Cai ${ }^{12 *}$, Kazuhiko Moji ${ }^{1}$, Xiaonan $\mathrm{Wu}^{3}$, Konglai Zhang ${ }^{4}$ \\ Accepted 26, February, 2007
}

\begin{abstract}
To investigate AIDS-related knowledge, attitudes, beliefs and practices (KABPs) among Chinese migrant laborers in east African cities, and to examine the current status of access to AIDS-related healthcare services, we conducted a cross-sectional study in Nairobi, Kenya, and Dar es Salaam, Tanzania. Of 121 male laborer participants who spoke neither English nor Swahili, 109 (90.9\%) had an education level of high school or less. The survey revealed that migrants' AIDS-related knowledge was poor, e.g., very few $(n=4,3.3 \%)$ were aware of the epidemiologic status of HIV in these two cities. Negative attitudes toward people living with HIV/AIDS (PLWHA) were widespread, and the majority $(\mathrm{n}=94,77.7 \%)$ did not make use of AIDS-related healthcare services or education. Although the main information resources on HIV/AIDS in China include television $(n=94,77.7 \%)$, books and newspapers $(n=78,64.5 \%)$ and radio $(n=51,42.1 \%)$, these sources were much less common in Nairobi and Dar es Salaam ( $\mathrm{p}<0.001$ for each). One third $(\mathrm{n}=44,36.4 \%)$ did not have any information resources in these two cities. These results indicate that Chinese migrant laborers are at risk of HIV infection in the two African cities. Appropriate education for the general population in China and for migrants in these two cities regarding HIV/AIDS, along with relevant information resources that are more accessible and useful for migrants in East Africa are therefore needed to minimize the risk of infection.

keywords: HIV; AIDS; Migration; Chinese; Kenya; Tanzania
\end{abstract}

\section{INTRODUCTION}

Mainland China is believed to be one of the most vulnerable areas with respect to HIV/AIDS, because of its vast population, high population density, and social and economic status [1-4]. A continuous increase in HIV/AIDS has been observed in China [1-3]. Although the Chinese government claims that the number of HIV-infected individuals will be as many as 1.5 million by 2010 , it has been suggested elsewhere that the number could exceed 10 million if no effective interventions are instituted [2-6]. The Chinese government has stated that HIV/AIDS is one of the greatest current public health threats to the country, and accordingly has proposed supportive policy making [7, 8]. However, preventive measures have faced many challenges.
One of the difficulties in HIV/AIDS control is that the Chinese population is characterized by its high mobility. The scale of domestic and international migration is extremely large compared to other nations [4, 9-13]. The number of domestic and international Chinese migrants is estimated to be some 120 and 22 million, respectively [14, 15]. It has been pointed out that these migrants are at greater risk of HIV infection than the general public; raising concern that this risky population could spread the disease outside its present highly prevalent areas [16-18]. Given the population size of 1.3 billion and the large scale of international migration, the HIV/AIDS epidemic in China has attracted international attention.

Although several previous works have investigated the epidemiology of HIV/AIDS among domestic migrants in

1 ) Research Center for Tropical Infectious Diseases, Nagasaki University Institute of Tropical Medicine, Nagasaki, Japan

2 ) Nagasaki University Graduate School of Biomedical Sciences, Nagasaki, Japan

3 ) School of Public Health, Fujian Medical University, Fuzhou, Fujian Province, China

4 ) Department of Epidemiology, Peking Union Medical College, Beijing, China

Guoxi Cai

Research Center for Tropical Infectious Diseases,

Nagasaki University Institute of Tropical Medicine,

1-12-4 Sakamoto, Nagasaki, Japan

Tel/Fax: +81958497869

E-mail:dm03047z@stcc.nagasaki-u.ac.jp 
China [12, 19-25], little is known about the present status among international Chinese migrants. These migrants, including thousands of temporary laborers, are prevalent not only in industrialized countries but also in cities in East Africa, but very little is known about the related risk of HIV infection in the east African cities. Since internationally mobile populations are at a high risk of acquiring HIV/AIDS and spreading the disease to other areas, it is important to clarify the HIV/AIDS characteristics of these migrants. In this study, we performed a cross-sectional survey in Nairobi, Kenya, and Dar es Salaam, Tanzania to assess several aspects of AIDS-related knowledge, attitudes, beliefs and practices (KABPs) among Chinese migrant laborers in those cities.

\section{MATERIALS AND METHODS}

\subsection{Study area}

According to the offices of the Xinhua News Agency in each location (Zhang $\mathrm{R}$ and Cui J, personal communication), the size of the Chinese migrant population is believed to be approximately 10,000 and 3,000 in Nairobi and Dar es Salaam, respectively (Figure 1). Although firm statistics are unavailable, many male migrant laborers at a sexually active age, separated from family members, and relatively uneducated, are engaged mainly in infrastructure development (e. g., construction) for Chinese companies and car repair services. The nationwide prevalence of HIV among pregnant women in Tanzania and Kenya was $8.1 \%$ and $9.4 \%$, respectively [1], which is far higher than that in China where it is estimated to be less than $0.1 \%$ [5]. Since no formal disease surveillance of the migrants has been conducted, there is no available information on the current epidemiology of HIV/

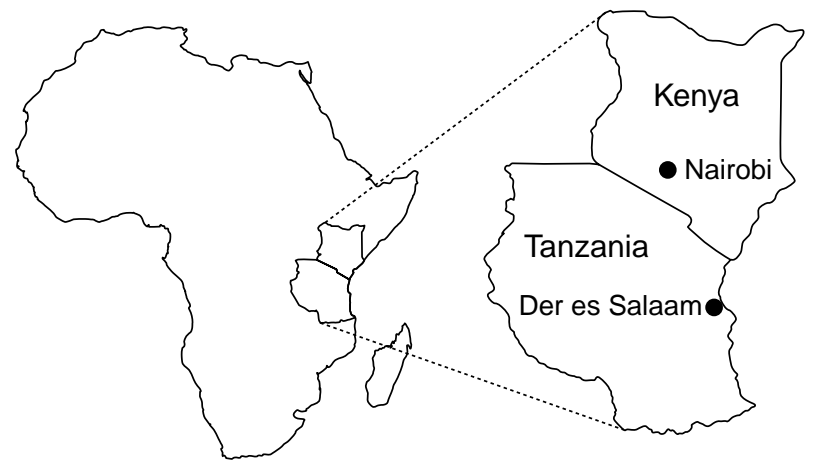

Figure 1. Study locations

Map of A) the African continent and B) the study locations in Nairobi, Kenya, and Dar es Salaam, Tanzania. Nairobi is the capital city of Kenya and has the largest population in East Africa (3-4 million inhabitants). Dar es Salaam lies on the east coast of Africa and has an estimated population of 2.5 million. Approximately 10,000 and 3,000 Chinese migrants are thought to be resident in Narobi and Dar es Salaam, respectively.
AIDS among these individuals (i.e., HIV prevalence and AIDS incidence). We chose these two cities for our investigation because of the relatively high potential for HIV infection and further disease spread.

\subsection{Survey}

We conducted a cross-sectional survey from 3-26 August 2005. With administrative support from the offices of the Xinhua News Agency in Nairobi and Dar es Salaam, and personal assistance from staff members of the Chinese Embassy in Kenya and Tanzania, we had the opportunity to directly visit Chinese construction sites in the two cities. Of the 36 sites in Nairobi with a total of 2,880 Chinese laborers, we visited 5 construction sites. We also visited 5 of the 22 sites in Dar es Salaam with a total of 1,320 laborers. The sampling of construction sites, where consent to cooperate in the investigation was obtained, was based on suggestions from the Xinhua News Agency (i.e., judgment sampling). With the assistance of site managers, 150 Chinese male laborers aged over 16 years were asked to volunteer as participants in the survey. Convenient sampling of participants was adopted for enrollment. Fifteen individuals were sampled at each site, resulting in a recruitment of 75 individuals from each city. Accordingly, 59 laborers (completion rate: $78.7 \%$ ) from Nairobi and $63(84.0 \%)$ from Dar es Salaam participated in the survey. one laborer in Dar es Salaam who had never heard of HIV/AIDS was excluded, and KABP were analyzed for the remaining 121 laborers.

Before conducting the questionnaire survey, we first asked 3 to 5 migrant worker leaders or those responsible for the Chinese groups at each site to participate in individual pilot interviews concerning their own sexual behavior and that of their colleagues. In the pilot interviews it was revealed that many of the laborers had experienced sexual intercourse with local commercial sex workers, usually without protection (e.g. a condom). We also learnt that none of the participants could speak either English or Swahili. Following the pilot interviews, we established the questionnaire items to be explored, covering basic demographic characteristics and potential risk behaviors. Subsequently, we requested other laborers at each site to voluntarily participate in an anonymous questionnaire survey, which focused on AIDS-related KABP and access to healthcare services and HIV/AIDS education.

\subsection{Questionnaire}

Our questionnaire was written in standard Chinese. We paid close attentions to validity and reliability. With respect to content validity, the draft of our questionnaire initially followed the contents of the KABP research package for HIV/AIDS suggested by the World Health Organization that 
has been widely adopted for studies of this type; its content validity being pre-tested and explicitly assessed in various settings [26]. The pilot interview was then conducted to determine what items should be explored and included in the actual survey. The final version of our questionnaire covered the following 7 sections:

A) Demographic characteristics

B) Access to information resources on HIV/AIDS while in China and Nairobi and Dar es Salaam, respectively

C) Knowledge on the prevention and prevalence of HIV in working countries

D) Attitudes toward people living with HIV/AIDS (PLWHA)

E) Fear of HIV infection as a measure of belief (i.e., recognition of potential risks during daily activity)

F) Previous experience with AIDS-related healthcare services and education

G) Willingness to utilize healthcare services for HIV/AIDS (i.e., to undergo HIV tests, AIDS counseling, and relevant education).

To avoid mass rejection of participation and to assure that the self-reported information reflected the honest responses of the participants, our questionnaire did not include detailed questions regarding sexual behavior. To investigate sexual behavior using self-administered questionnaires, different and specialized techniques are required [27 -29]. Data related to the participants' desire for health education and opinions for prevention of HIV/AIDS were sought in an open-ended fashion, while the remaining aspects were closed questions. Knowledge and attitude scores were measured by tallying the number of correct or supportive responses, which in total ranged from 0-17 and 0-12, respectively. Cronbach's alpha, which measures internal consistency (a measure of reliability) was as high as 0.80 and 0.84 for the knowledge and attitude scales, respectively. The questionnaire was applied in the different locations for this survey (i.e., Kenya and Tanzania), permitting an assessment of convergent validity. Moreover, a questionnaire that included almost the same items was employed for an investigation of Chinese medical experts in another study [30]. Other measures of validity and reliability could not be explicitly evaluated in this study and are discussed later (see Discussion section).

\subsection{Ethical considerations}

Written informed consent was obtained from all participants. The purpose of the survey and use of data were explained beforehand, and the anonymity and confidentiality of the responses were assured. The Ethics Committee of the School of Public Health, Fujian Medical University, China, approved this study.

\subsection{Statistical analyses}

Using the questionnaire-based information, demographic details, information regarding access to HIV/AIDS resources and KABP details were obtained for each individual. Among the demographic variables, only age and the duration of stay in the African cities were measured as continuous variables. Other variables, i.e. educational background, marital status, ethnic group and religion, were treated as dichotomous. Access to each information resource was measured as the proportion of those who responded positively among the respondents. Of the KABP findings (i.e., outcome variables), only knowledge (0-17) and attitudes (0-12) scores were treated as continuous variables. The other two outcomes, i.e. fear of contagion and willingness to undertake in healthcare services for HIV/ AIDS, were dichotomized. Willingness to utilize the healthcare services was assessed as a proportion of those who expressed at least one of three different categories of willingness (i.e., serological tests of HIV, AIDS-related counseling, or relevant education).

To examine the correlation between the two major outcomes (i.e., knowledge and attitude scores) and age and the duration of stay, we used a Spearman's rank correlation test. Associations between these outcomes and other dichotomous demographics variables were assessed by the MannWhitney test. The other two outcomes were also compared with background information, and Mann-Whitney and Fisher's exact tests were used to evaluate the associations. To compare the difference in access to information resources among migrants while in China and Africa, $\chi^{2}$ and Fisher's exact tests were used respectively. All statistical data were analyzed using SPSS software (SPSS ver 11.5; SPSS Inc., Chicago, IL) and the level of statistical significance was set at $\alpha=0.05$.

\section{RESULTS}

\subsection{Demographic variables and access to AIDS informa- tion resources}

Of the 150 laborers requested to volunteer as participants in the study, we obtained full responses from 122 individuals, achieving an overall completion rate of $81.3 \%$ (95\% Confidence Intervals (CI): 75.1, 87.6). One individual who had never heard of HIV/AIDS was excluded, and the responses from the remaining 121 individuals were used for subsequent analyses. Table 1 presents details on the demographic findings. The study participants were of a sexually active age (mean=35.7 [years], SD (Standard Deviation)= 8.8). The median (and 25-75 quartiles) duration of stay was $1.0(0.5-2.7)$ years. The majority $(n=109 ; 90.9 \%)$ were not university graduates, and nearly four fifths of the partici- 
Table1. Demographic characteristics of the participants $(n=121)$

\begin{tabular}{lcc}
\hline & Number & $\%$ \\
\hline Age [years] & 2 & \\
$10-19$ & 28 & 24.1 \\
$20-29$ & 43 & 37.1 \\
$30-39$ & 34 & 29.3 \\
$40-49$ & 9 & 7.8 \\
$50-59$ & & \\
Duration of stay [years] & 59 & 49.6 \\
$\quad<1$ & 43 & 36.1 \\
$1-4$ & 17 & 14.3 \\
$\quad>4$ & & \\
Educational background & 110 & 90.9 \\
$\quad$ High school or less & 11 & 9.1 \\
$\quad$ University graduate & & \\
Marital status & 26 & 21.5 \\
$\quad$ Single & 95 & 78.5 \\
$\quad$ Married & & \\
Ethnic group & 8 & 6.6 \\
$\quad$ Not Han & 113 & 93.4 \\
$\quad$ Han & & \\
Religion & 97 & 80.2 \\
$\quad$ No religion & 24 & 19.8 \\
$\quad$ Have religious beliefs & &
\end{tabular}

Table2. Access to information resources on HIV/AIDS in China and East Africa $(n=121)$

\begin{tabular}{|c|c|c|c|c|c|}
\hline \multirow[t]{2}{*}{ Information resource } & \multicolumn{2}{|c|}{ China } & \multicolumn{2}{|c|}{$\begin{array}{c}\text { East } \\
\text { Africa }^{\dagger}\end{array}$} & \multirow[t]{2}{*}{ p-value } \\
\hline & $\mathrm{N}^{\ddagger}$ & $\%$ & $\mathrm{~N}^{\ddagger}$ & $\%$ & \\
\hline TV & 94 & 77.7 & 20 & 16.5 & $<0.001$ \\
\hline Books and newspapers & 78 & 64.5 & 19 & 15.7 & $<0.001$ \\
\hline Radio & 51 & 42.1 & 3 & 2.5 & $<0.001^{\pi}$ \\
\hline Internet & 36 & 29.8 & 19 & 15.7 & $<0.01$ \\
\hline Friends & 32 & 26.4 & 38 & 31.4 & 0.39 \\
\hline Pamphlets & 31 & 25.6 & 9 & 7.4 & $<0.001^{\pi}$ \\
\hline Physicians & 18 & 14.9 & 16 & 13.2 & 0.71 \\
\hline AIDS counseling & 3 & 2.5 & 2 & 1.7 & $0.65^{\natural}$ \\
\hline Others ${ }^{\S}$ & 1 & 0.8 & 2 & 1.7 & $0.56^{\natural}$ \\
\hline No resources available & 1 & 0.8 & 44 & 36.4 & $<0.001^{\pi}$ \\
\hline
\end{tabular}

${ }^{\dagger}$ The two study locations, Nairobi and Dar es Salaam; ${ }^{\ddagger} \mathrm{N}$, the number of participants who responded to have used the specified information resources; " According to Fisher's exact test. The remainder were assessed by the $\chi^{2}$ test ${ }^{5}$ Those not specified as above (e.g., parents or sex partners).

pants $(n=95 ; 78.5 \%)$ were married. No significant differences was found between Nairobi and Dar es Salaam with respect to age $(\mathrm{P}=0.66)$, duration of stay $(\mathrm{P}=0.25)$, education $(\mathrm{P}=0.49)$, marital status $(\mathrm{P}=0.38)$, ethnic group $(\mathrm{P}=$ $0.46)$ or religion $(\mathrm{P}=0.36)$.

The questionnaire survey revealed that access to HIV/ AIDS information resources in China differed from that in Nairobi and Dar es Salaam (Table 2). In China, participants listed the major resources as television $(94 ; 77.7 \%)$, books
Table 3. Responses to questionnaire items related to knowledge of HIV/AIDS $(\mathrm{n}=121)$

\begin{tabular}{lr}
\hline \multicolumn{1}{c}{ Items (Correct answer) } & $\mathrm{N}^{\dagger}(\%)$ \\
\hline Mode of HIV transmission & $109(90.1)$ \\
Sexual intercourse (Yes) & $106(87.6)$ \\
Unsterilized needles (Yes) & $109(90.1)$ \\
From mother to infant during birth (Yes) & $84(69.4)$ \\
From mother to infant during breast feeding (Yes) & $112(92.6)$ \\
Illegal blood transfusion (Yes) & $99(81.8)$ \\
Dining with an HIV positive individual (No) & $102(84.3)$ \\
Shaking hands and hugging (No) & $81(66.9)$ \\
Mosquito bites (No) & $64(52.9)$ \\
Using public toilets or swimming pools (No) & $33(27.3)$ \\
Number who answered all the above 9 items cor- & \\
rectly &
\end{tabular}

Knowledge on prevention, basic knowledge, and epidemiology

Can proper condom use prevent HIV transmission? (Yes)

Can a person be judged HIV positive by their appearance? (No)

Is there any vaccine available against HIV? (No)

Can using sterilized needles contribute to HIV prevention? (Yes)

Can reducing blood transfusions contribute to HIV prevention? (Yes)

Is AIDS curable? (No)

What is the most common HIV transmission route in Africa? (Heterosexual transmission, $\mathrm{MCQ}^{\ddagger}$ )

What is the prevalence of HIV among adults in Kenya (Tanzania)? (7-9\%, $\mathrm{MCQ}^{\ddagger}$ )

$79(65.3)$

$81(66.9)$

$71(58.7)$

$79(65.3)$

$98(81.0)$

$64(52.9)$

$4(3.3)$

${ }^{\dagger} \mathrm{N}$, the number of those who correctly responded to the questions.

${ }^{\ddagger} \mathrm{MCQ}$, multiple choice question

and newspapers $(78 ; 64.5 \%)$, radio $(51 ; 42.1 \%)$, and the Internet $(36 ; 29.8 \%)$. Participants also indicated that they seldom experienced difficulties in collecting relevant information $(120 ; 99.9 \%)$. However, participants reported a dramatic reduction of resources in the two east African cities, with significant differences compared to those accessible in China: TV $(20 ; 16.5 \%, \mathrm{P}<0.001)$, books and newspapers $(19 ; 15.7 \%, \mathrm{P}<0.001)$, radio $(3 ; 2.5 \%, \mathrm{P}<0.001)$, and the Internet $(19 ; 15.7 \%, \mathrm{P}<0.01)$ were not often utilized by the migrants in either Nairobi or Dar es Salaam. In these cities, more than one third of participants claimed that they often felt that there were no accessible information resources available to them $(44 ; 36.4 \%, \mathrm{P}<0.001)$. No significant difference was observed between Nairobi and Dar es Salaam regarding the proportion of those having specified information resources.

\subsection{KABP findings}

The mean (and SD) knowledge score was estimated as 11.8 (3.4) with the overall proportion of correct responses 
Table 4. Responses to questionnaire items related to attitudes toward HIV/AIDS $(\mathrm{n}=121)$

\begin{tabular}{l} 
Items (supportive answer) \\
\hline Do you feel sympathy with PLWHA ${ }^{\ddagger}$ ?(Yes) \\
Do you think PLWHA receive what they deserve? (No) \\
Should PLWHA be isolated? (No) \\
Should PLWHA be allowed to continue in their job \\
and/or studies? (Yes) \\
Do you feel comfortable having social contact with \\
PLWHA? (Yes) \\
Do you feel comfortable having a meal with PLWHA? \\
(Yes) \\
Do you feel comfortable working in the same institute \\
as PLWHA? (Yes) \\
Do you feel comfortable working in the same building \\
as PLWHA? (Yes) \\
Do you feel comfortable working in the same office as \\
PLWHA? (Yes) \\
If your relative was infected with HIV, would you be \\
willing to care for him/her? (Yes) \\
If your friend was infected with HIV, would you be \\
willing to care for him/her? (Yes) \\
If infected with HIV, would you use a condom during \\
sexual intercourse with your partner? (Yes)
\end{tabular}

$\mathrm{N}^{\dagger}(\%)$

107(88.4)

107(88.4)

$66(54.5)$

$80(66.1)$

$37(30.6)$

$30(24.8)$

43(35.5)

$39(32.2)$

$15(12.4)$

90(74.4)

$73(60.3)$

$105(86.8)$

${ }^{\dagger} \mathrm{N}$, the number of those who responded as supportive toward PLWHA.
${ }^{\ddagger}$ PLWHA, People Living with HIV/AIDS. being $69.2 \%$ (95\% CI: 61.2, 77.6). Table 3 summarizes the descriptive results for the knowledge scale. Fifty-seven participants $(47.1 \%)$ did not know the most common route of HIV transmission in East Africa (i.e., heterosexual transmission), and very few $(n=4 ; 3.3 \%)$ correctly understood the status of HIV prevalence. No significant difference in knowledge score was observed between Kenya and Tanzania $(\mathrm{P}=0.89)$. The mean (and $\mathrm{SD}$ ) attitude score was 6.6 (3.1); detailed descriptive results are shown in Table 4. Although 107 respondents $(88.4 \%)$ answered that they felt sympathy for PLWHA, negative attitudes were remarkable: $55(45.5 \%)$ said that PLWHA should be isolated and 41 (33.9\%) responded that PLWHA should not be allowed to continue in their job or studies. No significant difference was revealed in the attitude score between Kenya and Tanzania $(\mathrm{P}=0.47)$.

The majority of participants $(n=104 ; 86.0 \%$ (95\% CI: $79.8,92.1)$ ) expressed fear of contagion, a measure of belief. With regard to the measure of practice, most participants (n $=94 ; 77.7 \%(95 \%$ CI: 70.3, 85.1)) responded that they had never received any AIDS-relevant health support or education during their time in Kenya and Tanzania. On the other

Table 5. Univariate analysis between KABP findings and the demographic variables

\begin{tabular}{|c|c|c|c|c|}
\hline & $\begin{array}{l}\text { Knowledge } \\
\text { score } \\
\text { Mean (SD) }\end{array}$ & $\begin{array}{l}\text { Attitudes } \\
\text { score } \\
\text { Mean } \\
\text { (SD) }\end{array}$ & $\begin{array}{c}\text { Fear of } \\
\text { contagion } \\
\mathrm{N}^{\S}(\%)\end{array}$ & $\begin{array}{c}\text { Willingness" } \\
\mathrm{N}^{\S}(\%)\end{array}$ \\
\hline \multicolumn{5}{|l|}{ Age $($ Mean $=35.7, \mathrm{SD}=8.8)$} \\
\hline \multicolumn{5}{|l|}{ Spearman's $\rho$ or } \\
\hline Mann-Whitney's Z-statistic & 0.12 & -0.19 & -0.13 & -0.83 \\
\hline P value & $0.20^{\dagger}$ & $0.05^{\dagger}$ & $0.90^{\ddagger}$ & $0.41^{\ddagger}$ \\
\hline \multicolumn{5}{|c|}{ Duration of stay (median=1.0) } \\
\hline \multicolumn{5}{|l|}{ Spearman's $\rho$ or } \\
\hline Mann-Whitney's Z-statistic & 0.104 & -0.134 & -1.557 & -0.932 \\
\hline$P$ value & $0.27^{\dagger}$ & $0.17^{\dagger}$ & $0.12^{\ddagger}$ & $0.35^{\ddagger}$ \\
\hline \multicolumn{5}{|l|}{ Educational background } \\
\hline High school or less & $11.9(3.1)$ & $6.4(3.0)$ & $86(84.3)$ & $94(92.2)$ \\
\hline University graduate & $13.7(1.7)$ & $7.7(2.8)$ & $11(100)$ & $10(90.9)$ \\
\hline$P$ value & $0.05^{\ddagger}$ & $0.22^{\ddagger}$ & $0.16^{! !}$ & $0.89 !$ \\
\hline \multicolumn{5}{|l|}{ Marital status } \\
\hline Single & $11.6(3.5)$ & $6.8(3.2)$ & $18(85.7)$ & $19(90.5)$ \\
\hline Married & $12.2(2.9)$ & $6.5(3.0)$ & $82(86.3)$ & 88 (92.6) \\
\hline$P$ value & $0.93^{\ddagger}$ & $0.83^{\ddagger}$ & $0.94 !$ & $0.74 ! !$ \\
\hline \multicolumn{5}{|l|}{ Ethnic group } \\
\hline Not Han & $12.8(2.1)$ & $8.0(4.0)$ & $5(71.4)$ & $6(85.7)$ \\
\hline Han & $12.0(3.3)$ & $6.6(3.1)$ & $98(86.7)$ & $105(92.9)$ \\
\hline$P$ value & $0.46^{\ddagger}$ & $0.51^{\ddagger}$ & $0.26^{! !}$ & $0.48^{! !}$ \\
\hline \multicolumn{5}{|l|}{ Religion } \\
\hline No religion & $12.1(3.0)$ & $6.7(3.1)$ & $82(85.4)$ & $89(92.7)$ \\
\hline Have religious beliefs & $12.1(3.1)$ & $6.2(2.4)$ & $21(87.5)$ & $22(91.7)$ \\
\hline$P$ value & $0.81^{\ddagger}$ & $0.71^{\ddagger}$ & $0.79 !$ & $0.86^{! !}$ \\
\hline
\end{tabular}

SD, standard deviation; " Willingness to utilize healthcare services for HIV/AIDS; ${ }^{5} \mathrm{~N}$, the number of those expressed fear of contagion or willingness; ${ }^{\dagger}$ According to Spearman's rank correlation test; ${ }^{\ddagger}$ According to Mann-Whitney test; "According to $\chi^{2}$ test. 
hand, almost all participants expressed willingness to utilize health education relevant to HIV/AIDS (98; 81.0\% $(95 \%$ CI: 74.0, 88.0)), serological testing for HIV infection (96; 79.3\% (95\% CI: 72.1, 86.6)) and AIDS counseling (104; $86.0 \%$ (95\% CI: 79.8, 92.1)). Consequently, $112(92.6 \%$ (95\% CI: 87.9, 97.2)) expressed willingness to utilize at least one of the three different categories. The proportion of those who expressed fear of contagion $(\mathrm{P}=0.46)$ and those willing to utilize healthcare services $(\mathrm{P}=0.10)$ was not significantly different between Nairobi and Dar es Salaam.

Univariate associations and correlations between the two major outcomes (i.e., knowledge and attitudes) and demographic variables are shown in Table 5. In the knowledge scale, those who graduated from university tended to show a significantly higher score $(\mathrm{P}=0.05)$. Moreover, the older individuals were significantly unlikely to be supportive toward PLWHA $(\rho=-0.193 ; \mathrm{P}=0.05)$. There was no significant association between the other two outcomes (i.e., fear of contagion and willingness to utilize healthcare services for HIV/AIDS) and demographic variables (Table 5).

\section{DISCUSSION}

This study showed that the knowledge of Chinese migrant laborers in the capital cities of Kenya and Tanzania with respect to HIV/AIDS is extremely poor, especially with regard to modes of transmission and prevention. Negative attitudes toward PLWHA were widespread. Moreover, the migrants had almost no access to useful information resources and thus were considered vulnerable to infection and spread of HIV/AIDS. Although our pilot survey implied that many of the migrants experienced risky sexual contact with local commercial sex workers, the migrants had few opportunities to receive education or to access healthcare services (i.e., including serological testing) related to HIV/AIDS. No significant difference was found between those working in Nairobi and Dar es Salaam with regard to information resources or KABP findings.

Although this study is the first to document the KABP of international Chinese migrants in developing countries, our findings are consistent with previous studies in industrialized countries $[17,31,32]$. In particular, because of the lack of information resources, international migrants are unable to access sufficient information and, consequently, opportunities for AIDS education and healthcare support are limited. The general characteristics of migrants, explored in earlier studies, reveal that the migrants are at a high risk of infection and tend to be potential spreaders of HIV/AIDS [13, 33-35]. Thus, effective countermeasures directly relevant to their culture and conveyed in their native language should be implemented. For example, AIDS education and healthcare services (e.g., AIDS counseling and HIV testing) in Chinese would help to provide support for these vulnerable migrants. Peer education on HIV/AIDS for international immigrants in the Netherlands was shown to be highly effective [36] and, given their mobility, could be an option for Chinese migrants.

It should be noted that the participants' poor knowledge reflects not only the limited information resources in Nairobi and Dar es Salaam but also the insufficiency of education in China prior to migration. Thus, although almost all participants responded that they had at least one information resource on HIV/AIDS in China, their poor knowledge implies the effective failure of education in China. Hence there is a clear need to improve this in the migrant's home country. A simple comparison of HIV prevalence between China and the countries in East Africa may suggest that the current risk of spreading HIV from China to East Africa is not as high as that in the opposite direction, but the spread would be heterogeneously enhanced by individuals at high risk, such as migrants. Thus, the spread from China to other countries is also a serious issue in view of the high potential to increase the prevalence of HIV/AIDS. Since the spread of HIV/AIDS through migration is not unidirectional (i.e., from East Africa to other locations) [37]; the potential risk of importing infection from a home country to East Africa should also be noted and investigated.

Attitudes toward PLWHA were found to be associated with age. Although it is difficult to directly intervene in negative attitudes, the origins are often associated with a lack of knowledge about on modes of transmission and a fear of HIV contagion [38, 39]. This implies that it is extremely important to provide at least basic education on HIV/AIDS. Given our survey results, the high proportion of those willing to partake in education and seek relevant healthcare services supports the suggestion that basic educational opportunities could improve the current situation.

There are three major limitations to our study. First, selection bias may have been introduced by the non-random sampling of construction sites and participants. It needs to be noted, therefore that the participants may not exactly represent Chinese migrants in the locations surveyed. Second, our selection of specific cities and participants (i.e., male laborers in two capital cities) may preclude significant generalizability because other locations and types of migrants were not covered by our survey. Third, the explicit assessment of validity and reliability of our questionnaire was limited, mainly due to an initial attempt to explore international Chinese migrants and due partly to a failure in our assessment. For example, (1) we failed to assess concurrent validity using different questionnaires and (2) an important aspect of the reliability measures, i.e. assuring re- 
peatability and reproducibility, was not evaluated in this study. Repeated measurements in other locations and samples are thus needed and will be the focus of our future studies aimed of investigating sexual behaviors in more detail.

The governments of the host countries and local health departments obviously cannot achieve the above improvements by themselves. Strong international cooperation between the responsible countries is therefore needed. Moreover, improvements do not necessarily have to be solely governmental. Non-governmental organizations could also take the initiative to provide health education and services, contributing to relevant prevention programs. In conclusion, because the health status and behavioral characteristics of Chinese migrants in international settings have not been sufficiently explored, we believe that the present study enhances such understanding and to facilitate further discussion on this issue.

\section{ACKNOWLEDGMENTS}

We thank Drs. Zhenning Feng, Weifen Dong, Liang Fan, and Rui Cai, and Mr. Xiang Wang and Mr. Jun Xie for assisting in our survey. We also thank Miss Ran Zhang and Mr. Weijian Shao for administrative support.

\section{REFERENCES}

1 . Joint United Nations Programme on HIV/AIDS and World Health Organization. AIDS Epidemic Update. 2004. Geneva: UNAIDS/WHO, 2004.

2 . China UN Theme Group on HIV/AIDS and China Ministry of Health. China responds to AIDS: HIV/AIDS situation and needs assessment report. Beijing: China UN Theme Group on HIV/AIDS and China Ministry of Health, 1997.

3 . China UN Theme Group on HIV/AIDS: China's Titanic Peril (Update of the AIDS situation and Needs Assessment Report). Beijing: China UN Theme Group on HIV/AIDS and China Ministry of Health, 2001.

4 . Kaufman J, Jing J. China and AIDS: the time to act is now. Science 2002; 296: 2339-2340.

5 . State Council AIDS Working Committee Office and UN Theme Group on HIV/AIDS in China. A Joint Assessment of HIV/AIDS Prevention, Treatment and Care in China (2004). Beijing: UNAIDS China Office, 2004.

6 . Zhang KL, Ma SJ. Epidemiology of HIV in China. BMJ 2002; 324: 803-804.

7 . Watts J. China's shift in HIV/AIDS policy marks turnaround on health. Pledge to provide free HIV tests shows China is starting to take action on combating the disease. Lancet 2004; 363: 1370-1371.

8 . Watts J. China faces up to HIV/AIDS epidemic. World AIDS day is marked by launch of huge public-awareness campaign. Lancet 2003; 362: 1983.

9 . Cohen J. HIV/AIDS in China. Poised for take off? Science 2004; 304: 1430-1432.

10 . Anonymous. China faces AIDS. Lancet 2001; 358: 773.

11. Abdullah AS. Spread of HIV and AIDS in China. Lancet 2000; 356: 1856.

12. Thomas J. HIV / AIDS in China: migrant population, drug injection responsible for increased transmission. AIDSlink 1998; 49: 12-14.

13. McCarthy M. Chinese AIDS experts call for more education to halt HIV epidemic. Lancet 1999; 354: 1800.

14. Zhu G. A preliminary study of international migration of the Chinese people. Chin J Popul Sci 1994; 6: 403-415.

15. Zhu G. A probe into reasons for international migration in Fujian Province. Chin J Popul Sci 1990; 2: 229-246.

16. Wu, Z. Rou, K. Cui, H. The HIV/AIDS epidemic in China: history, current strategies and future challenges. AIDS Educ Prev 2004; 16: 7-17.

17 . Tompkins M, Smith L, Jones K, Swindells S. HIV education needs among Sudanese immigrants and refugees in the Midwestern United States. AIDS Behav 2006; 10: 31933223.

18. UNAIDS. Population mobility and AIDS. Geneva: Joint United Nations Programme on HIV/AIDS, 2001.

19. He N, Detels R, Chen Z, Jiang Q, Zhu J, Dai Y, et al. Sexual behavior among employed male rural migrants in Shanghai, China. AIDS Educ Prev 2006; 18: 176-186.

20 . Hu Z, Liu H, Li X, Stanton B, Chen X. HIV-related sexual behaviour among migrants and non-migrants in a rural area of China: role of rural-to-urban migration. Public Health 2006; 120: 339-345.

21. Hesketh T, Li L, Ye X, Wang H, Jiang M, Tomkins A. HIV and syphilis in migrant workers in eastern China. Sex Transm Infect 2006; 82: 11-14.

22. Wang B, Li X, Stanton B, Fang X, Lin D, Mao R. HIVrelated risk behaviors and history of sexually transmitted diseases among male migrants who patronize commercial sex in China. Sex Transm Dis 2007; 34: 1-8.

23. Li X, Fang X, Lin D, Mao R, Wang J, Cottrell L, et al. HIV /STD risk behaviors and perceptions among rural-to-urban migrants in China. AIDS Educ Prev 2004; 16: 538-556.

24. Yang H, Li X, Stanton B, Fang X, Lin D, Mao R, et al. Willingness to participate in HIV/STD prevention activities among Chinese rural-to-urban migrants. AIDS Educ Prev 2004; 16: 557-570.

25. Anderson AF, Qingsi Z, Hua X, Jianfeng B. China's floating population and the potential for HIV transmission: a social-behavioural perspective. AIDS Care 2003; 15: 177185.

26 . World Health Organization. Research package: knowledge, attitudes, beliefs and practices on AIDS (KABP). Phase1. Geneva: World Health Organization, 1990.

27 . Dare OO, Cleland JG. Reliability and validity of survey data on sexual behaviour. Health Transit Rev 1994; 4: S93S110.

28. Buve A, Lagarde E, Carael M, et al. Interpreting sexual behaviour data: validity issues in the multicentre study on fac- 
tors determining the differential spread of HIV of four African cities. AIDS 2001; 15: S117-S126.

29 . Weinhardt LS, Forsyth AD, Carey MP, Jaworski BC, Durant LE. Reliability and validity of self-report measures of HIV-related sexual behavior: progress since 1990 and recommendations for research and practice. Arch Sex Behav 1998; 27: 155-180.

30 . Cai GX, Moji K, Honda S, Wu XN, Zhang KL. Inequality and unwillingness to care for people living with HIV/ AIDS: A survey of medical professionals in southeast China. AIDS Patient Care STDS 2007; in press.

31. Kang E, Rapkin BD, Springer C, Kim JH. The "Demon Plague" and access to care among Asian undocumented immigrants living with HIV disease in New York City. J Immigr Health 2003; 5: 49-58.

32. Gellert GA, Maxwell RM, Higgins KV, Mai KK, Lowery R, Doll L. HIV/AIDS knowledge and high risk sexual practices among southern California Vietnamese. Genitourin Med 1995; 71: 216-223.

33 . Anonymous. Migrant workers spreading HIV in Southeast Asia. AIDS Wkly Plus 1996: 1: 20-21.
34. Broring G, Van Duifhuizen R. Mobility and the spread of HIV / AIDS: a challenge to health promotion. AIDS Health Promot Exch 1993: 1: 1-3.

35. Hope KR. Population mobility and multi-partner sex in Botswana: implications for the spread of HIV/AIDS. Afr $\mathbf{J}$ Reprod Health 2001; 5: 73-83.

36. Kocken P, Voorham T, Brandsma J, Swart W. Effects of peer-led AIDS education aimed at Turkish and Moroccan male immigrants in The Netherlands. A randomised controlled evaluation study. Eur J Public Health 2001; 11: 153159.

37 . UNADIS and International Organization for Migration. Migration and AIDS. Int Migr 1998; 36: 445-468.

38. Feldmann TB, Bell RA, Stephenson JJ, Purifoy FE. Attitudes of medical school faculty and students toward acquired immunodeficiency syndrome. Acad Med 1990; 65: 464-466.

39. Boyd JS, Kerr S, Maw RD, Finnighan EA, Kilbane PK. Knowledge of HIV infection and AIDS, and attitudes to testing and counselling among general practitioners in Northern Ireland. Br J Gen Pract 1990; 40: 158-160. 